\section{Chronic subdural haematoma} associated with arachnoid cyst of the middle fossa in a soccer player: Case report and review of the

\section{literature}

\author{
Elena Beretta ${ }^{1 *}$, Michele Incerti ${ }^{1}$, Giuseppe Raudino ${ }^{1}$, \\ Gaspare F Montemagno ${ }^{1}$ and Franco Servadei ${ }^{2}$ \\ ${ }^{1}$ Department of Neurosurgery, Policlinico di Monza, Monza, Italy \\ ${ }^{2}$ Department of Neurosurgery, Humanitas University and Research Hospital, Milan, Italy
}

\section{Abstract}

Introduction: Arachnoid cyst (AC) is a congenital, benign, extra-axial lesion often found incidentally on intracranial imaging and makes up almost $1 \%$ of all intracranial masses. It arises from the splitting of arachnoid membranes with components similar to the cerebrospinal fluid. It's reported that AC can be complicated by chronic subdural haematoma in athletes with repeated head injuries

Case report: We describe a case of a soccer player with an AC that underwent surgery for a chronic subdural haematoma with full recovery.

Material and method: From a PubMed research, we found 14 relevant studies reporting a total of 15 patients who met the inclusion criteria: playing soccer, subdural hematoma and arachnoid cyst.

Results: Patients underwent different surgical treatment. In the case of hygroma with no midline shift, a conservative treatment was performed. In all cases the reported follow up was a full recovery.

Discussion: Soccer is not usually considered a contact sport related to a high risk of head trauma or shaking head. From our review we can postulate that a soccer player with AC has an augmented risk to have a subdural haemorrhage, more rarely intracerebral haemorrhage.

Conclusion: ACs are common meningeal abnormalities. They may bleed after minor head trauma, although it is rare. Asymptomatic patients with known AC should be monitored by a neurosurgeon and decision to engage this patient in soccer sport participation is still controversial.
More Information

*Address for Correspondence: Elena Beretta, Department of Neurosurgery, Policlinico di Monza, 20900 Monza, Italy,

Email: lamboqantum@gmail.com

Submitted: 22 April, 2020

Approved: 15 May, 2020

Published: 16 May, 2020

How to cite this article: Beretta $\mathrm{E}$, Incerti M, Raudino G, Montemagno GF, Servadei F. Chronic subdural haematoma associated with arachnoid cyst of the middle fossa in a soccer player: Case report and review of the literature. Arch Case Rep. 2020; 4: 032-037.

DOI: 10.29328/journal.acr.1001037

Copyright: (c) 2020 Beretta E, et al. This is an open access article distributed under the Creative Commons Attribution License, which permits unrestricted use, distribution, and reproduction in any medium, provided the original work is properly cited.

Keywords: Arachnoid cyst; Head trauma; Soccer player; Chronic subdural hematoma; Sports trauma

Abbreviations: AC: Arachnoid Cyst; CSDH: Chronic Subdural Hematoma; CSF: Cerebral Spinal Fluid; SDH: Subdural Hematoma

Check for updates

OPEN ACCESS

\section{Introduction}

Arachnoid cyst (AC) is a congenital, benign, extra-axial lesion often found incidentally on intracranial imaging and makes up almost $1 \%$ of all intracranial masses [1,2]. It arises from the splitting of arachnoid membranes with components similar to the cerebrospinal fluid (CSF) [1,2]. AC more frequently involves the left side with a male to female 3:1 ratio [3].

Chronic subdural haematoma (CSDH) often occurs in elderly patients with a head trauma more than 3 weeks prior to admission. CSDHs usually contain dark fluid, similar to motor oil, arising from acute subdural haemorrhage which evokes an inflammatory process [4].

Accumulating evidence pointing to $\mathrm{AC}$ can be complicated by CSDH in athletes with repeated head injuries [5].

Soccer is a popular sport worldwide with more than 1.4 million recorded players in Italy. Recent epidemiological data suggest that soccer player is a common cause of concussion and it may contribute to additional risk of haematoma formation after strike on the head by a soccer ball. The main problem for the Soccer Association is about allowing soccer player with 
a AC in soccer sport participation. Today's literature lacks of knowledge about this problem.

Here we present a case of a soccer player with AC associated with CSDH. Also we report the results of our systematic review of the literature to illustrate the epidemiology, diagnosis, treatment and prognosis of this rare entity in soccer players.

Soccer is not usually considered a contact sport related to a high risk of head trauma or shaking head. From our review we can postulate that a soccer player with AC has an augmented risk to have a subdural hemorrhage even with normal training.

\section{Case report}

A patient in his 20s, the soccer player came to neurosurgical attention because of 3 weeks of intense headache. There were no visual disturbances or other focal neurological signs. The CT scan showed a left temporal arachnoid cyst, Galassi type I (Figure 1) [6].

A brain MRI was planned as outpatient and he continued playing soccer.

After a period of regression of headache, 4 days before performing MRI, he presented intense headache accompanied by nausea and vomiting in the morning.

The MRI showed a left frontotemporal sub-acute subdural haematoma, $20 \mathrm{~mm}$ thick, isointense in T1 sequences and hyperintense in T2 Flair sequences with midline shift (Figure 2).

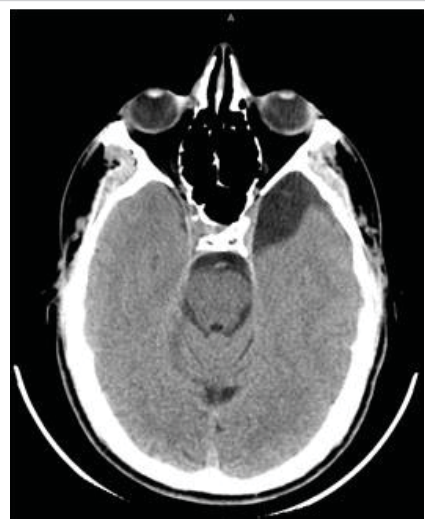

Figure 1: Axial CT scan showing a Galassi type 1 temporal Arachnoid Cyst on the left side.

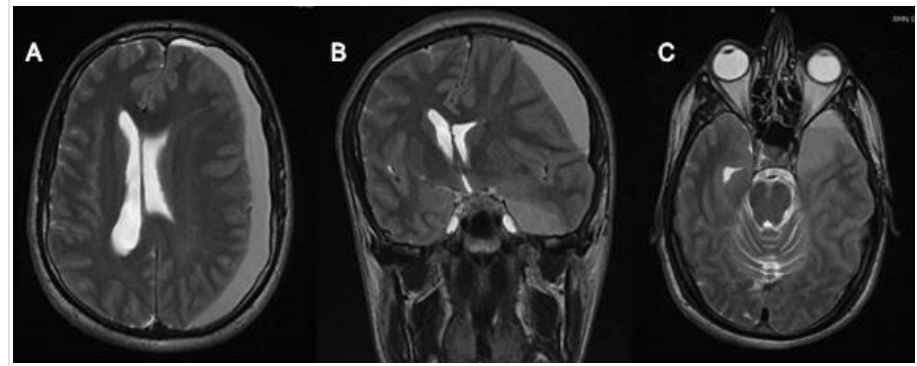

Figure 2: A) T2 MRI axial view showing a hyperintense left frontotemporal subacute hematoma, $20 \mathrm{~mm}$ thick with midline shift. B) T2 MRI coronal view showing the subdural hematoma with the same signal og the polar arachnoid cyst. C) T2 MRI axial view showing the communication of the subdural hematoma with the temporal arachnoid cyst.
He was admitted to our unit.

On admission, the neurological assessment was normal, the patient complained of headache, without vomiting and nausea. He denied the history of head trauma other than frequently heading the ball in competition and training.

The haematoma was evacuated and irrigated using isotonic saline solution through a single burr hole, positioned where the haematoma was wider. A closed system of subdural drainage was continued 3 days postoperatively. The AC was deliberately left intact. The postoperative CT scan showed near complete drainage of the haematoma (Figure 3).

His neurological status at discharge was normal; he returned to his daily activity after one week and he is headache-free at 6-months follow-up.

Soccer playing was contraindicated. The patient was followed up with CT scan at 1 and 6 months after surgery (Figure 4). The haematoma was totally drained and the AC was stable.

\section{Material and method}

\section{Literature search}

Published titles and abstracts in English language were searched for systematically across the electronic database PubMed. The search terms included MeSH terms and keyhole words. The search words included the following: arachnoid
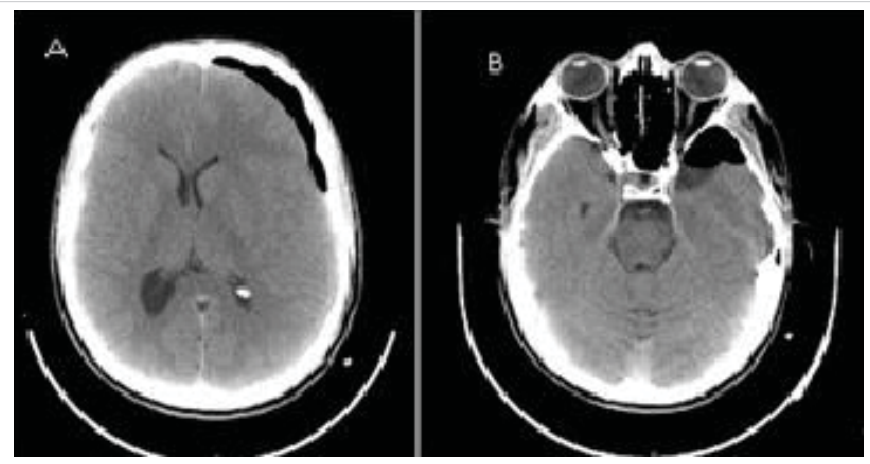

Figure 3: A) 24h post-operative CT axial view showing the near complete drainage of the hematoma. No midline shift. B) 24 h post-operative CT scan showing the AC occupied by air.

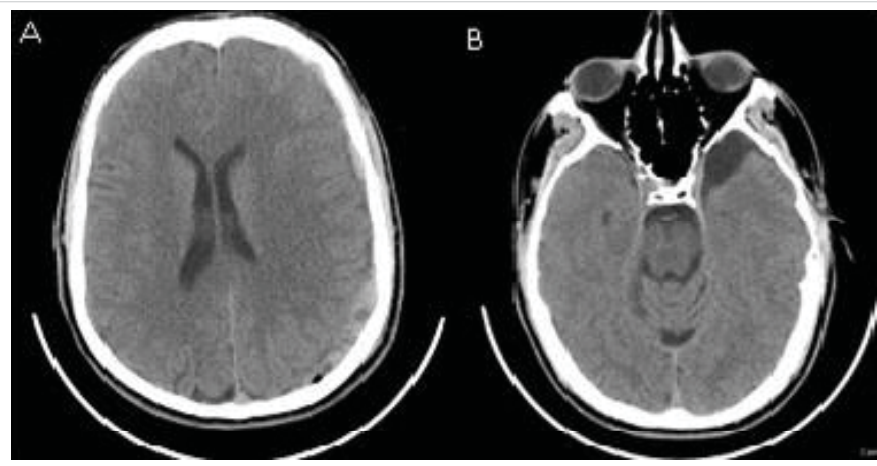

Figure 4: A) 6 months post-operative CT axial view showing the complete drainage of the hematoma. No midline shift. B) 6 months post-operative CT scan showing the $\mathrm{AC}$ with no hematoma. 
cyst, chronic subdural haematoma, sport injuries, and athletic injuries. Inclusion criteria were case report, case series or observational study of soccer player patient developing ACassociated CSDH. We also extrapolated from literature about sport-related CSDH in patients with AC, only studies including soccer-player patients. Studies with no sport specification were excluded.

\section{Results}

The literature search strategy and study selection process are summarized in table 1 [5,7-19].

Our search found 14 relevant studies reporting a total of 15 patients who met the inclusion criteria, 12 male and 3 female.

The articles were written from 1958 to 2015. The recent work of Wo, et al. [20] with a systematic review and their 14 cases of AC associated CSDH was excluded because they did not specify the type of sport involved. Sun, et al. [21] in 2017 reported the clinical analysis of 10 patients with CSDH associated to AC; this work was also excluded for being in Chinese and with no sport specification.

Patients were aged between 7 years old and 24 years old (mean 14.8 years).

Two patients on imaging presented subdural hygroma. The first, in the study of Offiah, had signs of raising intracranial pressure and midline shift and underwent a cystoperitoneal shunt [13], the second with no midline shift underwent conservative treatment [17].

13 patients on admission presented with $\operatorname{CSDH}[5,7-$
16,18,19]. 11 patients had midline shift $[5,7-9,11,12,15,16,18]$, in 1 case the midline structure was on axis [10]. and in 2 cases there was no mention on midline shift or other signs of raised intracranial pressure $[14,19]$.

Symptoms reported varied from headache and successively episode of vomiting, in particular in the morning. The onset of symptoms ranged between 4 days and 10 weeks (mean 39,5 days) from a supposed head trauma.

About surgical procedure, in our review 7 patients underwent single burr hole drainage and irrigation of the CSDH; the cyst was left intact as in our case $[9,12,14$ $16,18,19]$. Six patients underwent an open craniotomy with cyst fenestration $[5,7,8,11,13,19]$ In one of these, the patient with the subdural hygroma and midline shift, a cistoperitoneal shunt was also performed [13]. In one case the surgical procedure was not well specified [10]. In the case of subdural hygroma with no midline shift, a conservative treatment was done [17].

Intracystic hemorrhage was seen in 6 patients $[5,7-$ $9,11,15]$. In 6 patients there was no evidence of intracranial hemorrhage $[9,10,12,14,18,19]$ In one case this particular was not reported [16].

There was not recurrence from the first surgery in 13 cases [5,7-12,14,15,17-19], whereas in 2 cases no follow up was reported $[13,16]$.

Based on the limited information provided, we can say that in all cases the reported follow up was a full recovery.

\begin{tabular}{|c|c|c|c|c|c|c|c|c|c|c|c|}
\hline Authors & year & sex & age & pathology & \begin{tabular}{|l|}
$\begin{array}{l}\text { midline } \\
\text { shift }\end{array}$ \\
\end{tabular} & $\begin{array}{l}\text { cyst } \\
\text { intact }\end{array}$ & treatment & outcome & \begin{tabular}{|l|} 
onset \\
symptoms \\
\end{tabular} & $\begin{array}{l}\text { intracystic } \\
\text { hemorrage }\end{array}$ & recurrence \\
\hline Oliver $^{7}$ & 1958 & M & 21 & $\mathrm{SDH}$ & yes & no & open craniotomy & good & 10 weeks & yes & no \\
\hline Maeda et $\mathrm{al}^{8}$ & 1993 & M & 14 & SDH & yes & no & open craniotomy & good & 2 months & yes & no \\
\hline Kawanishi et al. ${ }^{9}$ & 1999 & M & 11 & $\mathrm{SDH}$ & yes & yes & 2 burr holes & good & 6 weeks & yes & no \\
\hline Kawanishi et al. ${ }^{9}$ & 1999 & M & 14 & $\mathrm{SDH}$ & yes & yes & 2burr holes & good & 2 days & no & no \\
\hline Chillala et al. ${ }^{10}$ & 2001 & M & 21 & $\mathrm{SDH}$ & no & no & $\begin{array}{l}\text { surgery unspecified } \\
\text { - cyst dreinage }\end{array}$ & good & 3 weeks & no & no \\
\hline $\begin{array}{l}\text { Prabhu \& } \\
\text { Bailes }^{11} \\
\end{array}$ & 2002 & $\mathrm{~F}$ & 16 & SDH & yes & no & open craniotomy & NR & & yes & no \\
\hline $\begin{array}{l}\text { Demetriades et } \\
\mathrm{al}^{12}\end{array}$ & 2004 & M & 24 & $\mathrm{SDH}$ & yes & yes & bur hole & good & 6 weeks & no & no \\
\hline Offiah et al. ${ }^{13}$ & 2006 & M & 8 & hygroma & yes & no & $\begin{array}{l}\text { open craniotomy, } \\
\text { cystoperitoneal } \\
\text { shunt }\end{array}$ & good & & hygroma & $\mathrm{NR}$ \\
\hline Miele et al. ${ }^{5}$ & 2006 & F & 16 & $\mathrm{SDH}$ & yes & no & open craniotomy & good & 4 days & yes & no \\
\hline $\begin{array}{l}\text { Domenicucci et } \\
\text { al. }{ }^{14}\end{array}$ & 2009 & M & 7 & $\mathrm{SDH}$ & NR & yes & bur hole & good & & no & no \\
\hline Zeng et al. ${ }^{15}$ & 2011 & M & 16 & $\mathrm{SDH}$ & yes & yes & bur hole & good & 4 weeks & yes & no \\
\hline Isik et al. ${ }^{16}$ & 2011 & M & 13 & $\mathrm{SDH}$ & yes & NR & bur hole & good & & & NR \\
\hline Maher et al. ${ }^{17}$ & 2013 & F & 12 & hygroma & no & NR & no surgery & good & days & hygroma & no \\
\hline $\begin{array}{l}\text { Edmondson et } \\
\text { al. }^{18}\end{array}$ & 2014 & M & 14 & $\mathrm{SDH}$ & yes & yes & bur hole & good & 10 weeks & no & no \\
\hline Takizawa et al. ${ }^{19}$ & 2015 & M & 15 & SDH & NR & no & open caniotomy & good & 8 weeks & no & no \\
\hline
\end{tabular}




\section{Discussion}

The incidence of $\mathrm{AC}$ in general population is estimated to be $0.2 \%$ to $1.7 \%[22,23]$.

ACs arise from a developmental aberration involving duplication or splitting of the arachnoid membrane. They contains clear CSF although when the content in protein is mildly elevated, it could suggest isolation of the AC from CSF pathways. They can present at any age with symptoms that often are mild and not specific. AC in the middle fossa are found more commonly in males (3:1) in the left side [24].

Diagnosis is often incidental. Most AC remain stable in size but $10 \%$ will show increase in time. The mechanism proposed is due to CSF secretion within cyst and a valve mechanism that entraps CSF, or enlargement due to an osmotic gradient through the cyst wall [25].

The association of $\mathrm{AC}$ and $\mathrm{CSDH}$ was first described in 1971 [26].

But it has been widely accepted that intracranial AC is a risk factor for CSDH in children and young adults [20].

In the study of Wester and Helland, CSDH occurs more frequently in temporal AC (6.5\%) [24]. In the same study there was no statistical significance in haematoma frequency between small, middle sized and large temporal cyst (Galassi I-III) [3.

Hypotheses on CSDH formation can be categorized in different groups. First the minor trauma can damage veins around the AC or the veins in the Sylvian fissure, distended by the cyst producing a CSDH $[27,28]$. The second explanation is that the cyst wall is stiffer and less compliant than the surrounding brain. This produce a distension and rupture of the bridging veins around the cyst wall during trauma [28-30]. Another theory suggested that the AC is ruptured by head trauma producing a subdural hygroma, which transforms in haematoma [31]. CSF with or without blood may leak into the subdural space and this results in the outer membrane formation under the dura mater. This forms fragile neocapillaries with degenerated endothelium causing repeated bleeding in this space accompanied by local hyperfibrinolysis and forming a CSDH [32]. Wester, et al. during surgical procedure in their patients, described the facility of detaching the AC membrane from the dura, and the blood oozing during the cyst membrane collapse. This bleeding was from small vascular openings on the dura surface. From their study they sustained that a moderate head trauma can cause a detachment of the AC membrane from the dura causing a bleeding episode [24]. This mechanism was also described by Page, et al. in 1987 [28].

In support to these theories, Haines, et al. in their microscopic study described the dural border cells extending from the dural and adhering to the arachnoid membrane delimitating a 'potential space' called the 'subdural compartment'. This is a virtual space until a traumatic event open it [33]. The presence of the AC weakens the subdural compartment at the level of the junction with the dura and favors bleeding, causing a minimal SDH that evolves into CSDH [14].

Rupture rate is been reported at $2.27 \%$ and $6 \%$. Risk factor for rupture is the size $(>5 \mathrm{~cm})$ and preceding head trauma, even minor head trauma [22].

In his review Zuckerman describes skull thinning in $60 \%$ of cases of AC associated to a CSDH. This fact is an important finding for soccer players because it can lead a slight higher risk of hemorrhage due to a minor head trauma [34].

In the case we present, the initial bleeding is presumed to have been the cause of the onset of headache, while the report of the first radiological imaging was negative for hemorrhage and it's likely that a small hemorrhagic collection was present but unrecognized on CT scan. Subsequent rebleed and or growth of the subdural collection due to osmotic influx, may explain the increased size seen in the MRI after a week.

Diagnosis is usually incidental and patients present signs of increased intracranial pressure. If the CT diagnosis shows an isodense AC due to the presence of intracystic haematoma, the MRI is the first-choice radiological [14].

In literature there are 2 cases of subdural hygroma associated with an AC after a minor trauma in a soccer player. ${ }^{13,17}$ In the study of Maher et al. symptomatic patients were treated conservatively with Acetazolamide and a close follow-up was performed with good results. Surgery was preferred in patients with severe symptoms and neurological impairment and in patients whose condition was refractory to conservative management. In their practice they attempt to treat with surgical fenestration, reserving shunt placement for those with treatment failures [17].

Neurosurgical management is for large, symptomatic CSDH with midline shift. The surgical options are burr hole drainage with drainage placement for 3-5 days. Sometimes a craniotomy was done with or without cyst fenestration.

Recently, most studies have suggested that burr hole irrigation and drainage is the first-choice treatment. Only in the event of recurrence after this procedure, does removal of the membranes and $\mathrm{AC}$ fenestration through a craniotomy become necessary $[14,29,35]$.

Musluman, et al. describe a management algorithm for patients with CSDH AC associated. In Galassi type I and II the burr hole drainage is the first-choice treatment, leaving the AC membrane intact. In Galassi type III if there is swelling and CSF fistula on the operation site or recurrence of the hematoma, additional subduroperitoneal shunting may be performed after the burr hole drainage. In their study they reported that AC fenestration carries some risk of morbidity, such as rebleeding, epidural hematoma or subdural hygroma; so they assume that treating the $\mathrm{AC}$ during hematoma drainage is not necessary unless the AC causes symptoms [36]. 
In our opinion there are no sufficient data to explain if we need to treat the SDH and perform associated cyst fenestration. In our study the CSDH communicates with the cyst, so we may hypothesise that there's an auto fenestration of the cyst during CSDH formation (Figure 2).

The excellent post-operative outcome in the 10 patients and the one in our unit suggests that patients with AC associated CSDH can be treated with burr-hole drainage alone, without cyst fenestration. None of the patients described in literature had no recurrence.

Aoki and Sakai and later Servadei, et al., during surgery found bleeding from the leptomeningeal vessels between the outer membrane of the $\mathrm{AC}$ and the dura of the temporal bone during cyst fenestration. They propose a careful coagulation at the interface between the outer membrane and the dura during $\mathrm{AC}$ fenestration $[37,38]$.

CSDH associate to $\mathrm{AC}$ has been observed in several contact sports $[9,12,30]$. There are few reports that specifically report on soccer players with no known direct trauma other than repeated heading the ball during games and practice. The onset of symptoms has ranged from several hours to months $[9,12]$.

In soccer players the mechanism of injury may be different. In some cases there's a direct forceful head injury, in other cases, as in ours, the injury seems to have arisen from repetitive routine heading the ball.

Recent data suggest that soccer related head injury is a common cause of sport related concussion with documented risk of intracranial injury and haematoma.

Screening for AC in sports may not be cost-effective, physicians involved in sports medicine, should be aware of this condition and should have a high index of suspicion whenever a diagnosis of intracranial arachnoidal cyst is made.

\section{Conclusion}

$\mathrm{AC}$ are common meningeal abnormalities. They may bleed after minor head trauma, although it is rare. Asymptomatic patients with known AC should be monitored by a neurosurgeon and decision to engage this patient in soccer sport participation is still controversial.

Although soccer in not considered a contact sport, recent epidemiological data suggest that it is a common cause of concussion. In addition there's a risk of significant intracranial injury and haematoma formation after a strike on the head by a soccer ball, and the AC may contribute to an additional risk. So the question is: should individuals with a known diagnosis of AC be allowed to compete in contact sports and even in soccer?

At least patients and their family members should be carefully informed that the risk of a traumatically induced hemorrhage is present but uncertain.
From our study, when a CSDH occurs in AC patients, we recommend a minimal invasive treatment, with a burr hole drainage, because of shorter hospitalization duration and a lower risk of complications.

\section{Limitations}

$\mathrm{CSDH}$ associated to $\mathrm{AC}$ in soccer player is a rare entity; most of the data in literature are case reports, letters to the editor or with no specification of the sport related to. So statistical analysis is inappropriate at the present. Consequently our study might not reflect the exact epidemiological situation.

\section{Funding}

This work did not receive any specific grant from funding agencies in the public, commercial or not-for-profit sectors.

\section{References}

1. Galassi E, Pazza G, Gaist G, Giuliani G, Pozzati E. Arachnoid cysts of the middle cranial fossa: experience with 77 cases treated surgically. Acta Neurochir Suppl (Wien). 1988; 42: 201-204.

PubMed: https://www.ncbi.nlm.nih.gov/pubmed/3189009

2. Heier LA, Zimmermann RD, Amster JL, Gandy SE, Deck MD. Magnetic resonance imaging of arachnoid cyst. Clin Imaging .1989; 13:281-291. PubMed: https://www.ncbi.nlm.nih.gov/pubmed/2598110

3. Wester K. Peculiarities of intracranial arachnoid cysts: location, sidedness, and sex distribution in 126 consecutive patients. Neurosurgery. 1999; 45: 775-779.

PubMed: https://www.ncbi.nlm.nih.gov/pubmed/10515470

4. Lee KS. Natural history of chronic subdural hematomas: a review. J Neurosurg. 2004; 18:351-358.

PubMed: https://www.ncbi.nlm.nih.gov/pubmed/14742149

5. Miele VJ, Bailes JE, Martin NA. Participation in contact or collision sports in athletes with epilepsy, genetic risk factors, structural brain lesions, or history of craniotomy. Neurosurg Focus. 2006; 21: E9. PubMed: https://www.ncbi.nlm.nih.gov/pubmed/17112199

6. Galassi E, Tognetti F, Gaist G, Fagioli L, Frank F, et al. CT scan and metrizamide CT cisternography in arachnoid cysts of the middle cranial fossa: classification and pathophysiological aspects. Surg Neurol. 1982; 17: 363-369.

PubMed: https://www.ncbi.nlm.nih.gov/pubmed/7089853

7. Oliver LC. Primary arachnoid cysts; report of two cases. Br Med J 1958; 1:1147-1149.

PubMed: https://www.ncbi.nlm.nih.gov/pubmed/13536443

8. Maeda M, Kawamura Y, Handa Y, Kubota T, Ishii Y. Value of MR imaging in middle fossa arachnoid cyst with intracystic and subdural hematoma. Eur J Radiol. 1993; 17: 145-147.

PubMed: https://www.ncbi.nlm.nih.gov/pubmed/8293737

9. Kawanishi A, Nakayama M, Kadota K. Heading injury precipitating subdural hematoma associated with arachnoid cysts-two case reports. Neurol Med Chir (Tokyo). 1999; 39: 231-233.

PubMed: https://www.ncbi.nlm.nih.gov/pubmed/10344112

10. Chillala S, Read C, Evans PA. An unusual case of subdural haematoma presenting to the accident and emergency department. Emerg Med J. 2001; 18: 308-309.

PubMed: https://www.ncbi.nlm.nih.gov/pubmed/11435376

11. Prabhu VC, Bailes JE. Chronic subdural hematoma complicating arachnoid cyst secondary to soccer-related head injury: case report. Neurosurgery. 2002; 50:195-197.

PubMed: https://www.ncbi.nlm.nih.gov/pubmed/11844251 
12. Demetriades AK, McEvoy AW, Kitchen ND. Subdural haematoma associated with an arachnoid cyst after repetitive minor heading injury in ball games. Br J Sports Med. 2004; 38: E8.

PubMed: https://www.ncbi.nlm.nih.gov/pubmed/15273201

13. Offiah C, St Clair Forbes W, Thorne J. Non-haemorrhagic subdura collection complicating rupture of a middle cranial fossa arachnoid cyst. Br J Radiol 2006; 79:79-82.

PubMed: https://www.ncbi.nlm.nih.gov/pubmed/16421410

14. Domenicucci M, Russo N, Giugni E, Pierallini A. Relationship between supratentorial arachnoid cyst and chronic subdural hematoma: neuroradiological evidence and surgical treatment. J Neurosurg. 2009; 110: 1250-1255.

PubMed: https://www.ncbi.nlm.nih.gov/pubmed/18976058

15. Zeng T, Shi SS, Lin YF. Chronic subdural hematoma associated with sylvian arachnoid cyst in juvenile athletes: report of two cases and literature review. Chin J Traumatol. 2011; 14: 174-177.

PubMed: https://www.ncbi.nlm.nih.gov/pubmed/21635806

16. Isik HS, Yildiz O, Ceylan Y. Chronic subdural hematoma caused by soccer ball trauma associated with arachnoid cyst in childhood: case report. J Neurol Sci (Turk). 2011; 28: 398-401.

17. Maher CO, Garton HJ, Al-Holou WN, Trobe JD, Muraszko KM, et al. Management of subdural hygromas associated with arachnoid cysts. J Neurosurg Pediatr. 2013; 12: 434-443.

PubMed: https://www.ncbi.nlm.nih.gov/pubmed/24011368

18. Edmondson L, Upshaw JE, Tuuri RE. A 14-year-old male with a 10week history of headaches. Pediatr Ann. 2014;43: 222-223.

PubMed: https://www.ncbi.nlm.nih.gov/pubmed/24972416

19. Takizawa K, Sorimachi T, Honda Y, Ishizaka H, Baba T, et al. Chronic Subdural Hematomas Associated with Arachnoid Cysts: Significance in Young Patients with Chronic Subdural Hematomas. Neurol Med Chir (Tokyo). 2015; 55: 727-734.

PubMed: https://www.ncbi.nlm.nih.gov/pmc/articles/PMC4605080/

20. Wu X, Li G, Zhao J, Zhu X, Zhang Y, Hou K. Arachnoid Cyst-Associated Chronic Subdural Hematoma: Report of 14 Cases and a Systematic Literature Review. World Neurosurg. 2018; 109:118-130.

PubMed: https://www.ncbi.nlm.nih.gov/pubmed/28962953

21. Sun J, Wang W, Wang D, An S, Xue L, et al. Clinical analysis of 10 patients of chronic subdural hematoma associated with arachnoid cyst. Zhonghua Yi Xue Za Zhi. 2017; 23; 97: 1502-1504.

PubMed: https://www.ncbi.nlm.nih.gov/pubmed/28535643

22. Cress M, Kestle JR, Holubkov R, Riva-Cambrin J. Risk factors for pediatric arachnoid cyst rupture/hemorrhage: a case-control study. Neurosurgery. 2013; 72: 716-722.

PubMed: https://www.ncbi.nlm.nih.gov/pubmed/23313978

23. Katzman GL, Dagher AP, Patronas NJ. Incidental findings on brain magnetic resonance imaging from 1000 asymptomatic volunteers. JAMA. 1999; 282: 36-39.

PubMed: https://www.ncbi.nlm.nih.gov/pubmed/10404909

24. Wester K, Helland CA. How often do chronic extra-cerebral haematomas occur in patients with intracranial arachnoid cysts? J Neurol Neurosurg Psychiatry. 2008; 79: 72-75.

PubMed: https://www.ncbi.nlm.nih.gov/pubmed/17488784

25. Al-Holou WN, Terman S, Kilburg C, Garton HJ, Muraszko KM, et al. Prevalence and natural history of arachnoid cysts in adults. J Neurosurg. 2013; 118: 222-231.

PubMed: https://www.ncbi.nlm.nih.gov/pubmed/23140149
26. Robinson R. Congenital cyst of the brain: arachnoid malformations. Progr Neurosurg. 1971; 4: 133-174.

27. LaCour F, Trevor R, Carey M. Arachnoid cyst and associated subdural hematoma. Observations on conventional roentgenographic and computerized tomographic diagnosis. Arch Neurol. 1978; 35: 84-89. PubMed: https://www.ncbi.nlm.nih.gov/pubmed/623534

28. Page A, Paxton RM, Mohan D. A reappraisal of the relationship between arachnoid cysts of the middle fossa and chronic subdural haematoma. J Neurol Neurosurg Psychiatry. 1987; 50:1001-1007. PubMed:: https://www.ncbi.nlm.nih.gov/pubmed/3655804

29. Takayasu T, Harada K, Nishimura S, Onda J, Nishi T, et al. Chronic subdural hematoma associated with arachnoid cyst. Two case histories with pathological observations. Neurol Med Chir (Tokyo). 2012; 52: 113-117.

PubMed: https://www.ncbi.nlm.nih.gov/pubmed/22362297

30. Parsch CS, Krauss J, Hofmann E, Meixensberger J, Roosen K. Arachnoid cysts associated with subdural hematomas and hygromas: analysis of 16 cases, long-term follow-up, and review of the literature. Neurosurgery. 1997; 40: 483-490.

PubMed: https://www.ncbi.nlm.nih.gov/pubmed/9055286

31. Kusuno K, Yoshida Y, Takahashi A, Ishii S. Chronic subdural hygroma caused by rupture of arachnoid cyst. As a probable course of chronic subdural hematoma-case report. Neurol Med Chir (Tokyo). $1984 ; 24$ 349-354.

PubMed: https://www.ncbi.nlm.nih.gov/pubmed/6206419

32. Shim YS, Park CO, Hyun DK, Park HC, Yoon SH. What are the causative factors for a slow, progressive enlargement of a chronic subdural hematoma? Yonsei Med J. 2007; 30; 48: 210-217. PubMed: https://www.ncbi.nlm.nih.gov/pubmed/17461518

33. Haines DE, Harkey HL, Al-Mefty O. The "subdural" space: a new look at an outdated concept. Neuurosurgery 1993; 32:111-120. PubMed: https://www.ncbi.nlm.nih.gov/pubmed/8421539

34. Zuckerman SL, Prather CT, Yengo-Kahn AM, Solomon GS, et al. Sport-related structural brain injury associated with arachnoid cysts: a systematic review and quantitative analysis. Neurosurg Focus. 2016; 40: E9.

PubMed: https://www.ncbi.nlm.nih.gov/pubmed/27032926

35. Mori K, Yamamoto T, Horinaka N, Maeda M. Arachnoid cyst is a risk factor for chronic subdural hematoma in juveniles: twelve cases of chronic subdural hematoma associated with arachnoid cyst. J Neurotrauma. 2002; 19:1017-1027.

PubMed: https://www.ncbi.nlm.nih.gov/pubmed/12482115

36. Müslüman AM, Özöner B, Kirçelli A, Can SM, Yilmaz A, et al. Chronic subdural hematoma associated with arachnoid cyst of the middle fossa : Surgical treatment and mid-term results in fifteen patients. Turk Neurosurg. 2018; 28: 776-782.

PubMed: https://www.ncbi.nlm.nih.gov/pubmed/29131236

37. Aoki N, Sakai T. Intraoperative subdural hematoma in a patient with arachnoid cyst in the middle cranial fossa. Childs Nerv Syst. 1990; 6: 44-46.

PubMed: https://www.ncbi.nlm.nih.gov/pubmed/2311116

38. Servadei F, Vergoni G, Frattarelli M, Pasini A, Arista A, et al. Arachnoid cyst of middle cranial fossa and ipsilateral subdural haematoma: diagnostic and therapeutic implications in three cases. $\mathrm{Br} \mathrm{J}$ Neurosurg. 1993; 7: 249-253.

PubMed: https://www.ncbi.nlm.nih.gov/pubmed/8338645 